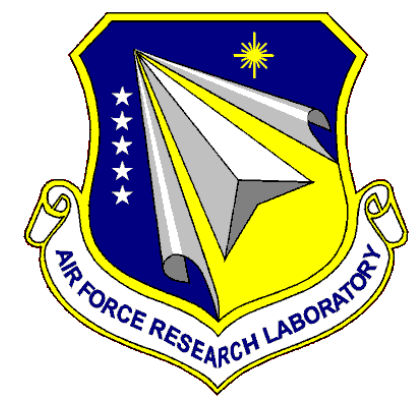

\title{
AFRL-RX-WP-JA-2014-0208
}

\section{MEASURING REFRACTIVE INDEX USING THE FOCAL DISPLACEMENT METHOD (POSTPRINT)}

Shekhar Guha

AFRL/RXAP

MAY 2014

Interim Report

Distribution A. Approved for public release; distribution unlimited. See additional restrictions described on inside pages

\section{STINFO COPY}

(C) 2014 Optical Society of America

AIR FORCE RESEARCH LABORATORY

MATERIALS AND MANUFACTURING DIRECTORATE WRIGHT-PATTERSON AIR FORCE BASE, OH 45433-7750

AIR FORCE MATERIEL COMMAND

UNITED STATES AIR FORCE 


\section{NOTICE AND SIGNATURE PAGE}

Using Government drawings, specifications, or other data included in this document for any purpose other than Government procurement does not in any way obligate the U.S. Government. The fact that the Government formulated or supplied the drawings, specifications, or other data does not license the holder or any other person or corporation; or convey any rights or permission to manufacture, use, or sell any patented invention that may relate to them.

This report was cleared for public release by the USAF 88th Air Base Wing (88 ABW) Public Affairs Office (PAO) and is available to the general public, including foreign nationals.

Copies may be obtained from the Defense Technical Information Center (DTIC) (http://www.dtic.mil).

AFRL-RX-WP-JA-2014-0208 HAS BEEN REVIEWED AND IS APPROVED FOR PUBLICATION IN ACCORDANCE WITH ASSIGNED DISTRIBUTION STATEMENT.

//Signature//

SHEKHAR GUHA

Photonic Materials Branch

Functional Materials Division
//Signature//

CHRISTOPHER D. BREWER, Chief

Photonic Materials Branch

Functional Materials Division

//Signature//

TIMOTHY J. BUNNING, Chief

Functional Materials Division

Materials and Manufacturing Directorate

This report is published in the interest of scientific and technical information exchange, and its publication does not constitute the Government's approval or disapproval of its ideas or findings. 
display a currently valid OMB control number. PLEASE DO NOT RETURN YOUR FORM TO THE ABOVE ADDRESS.

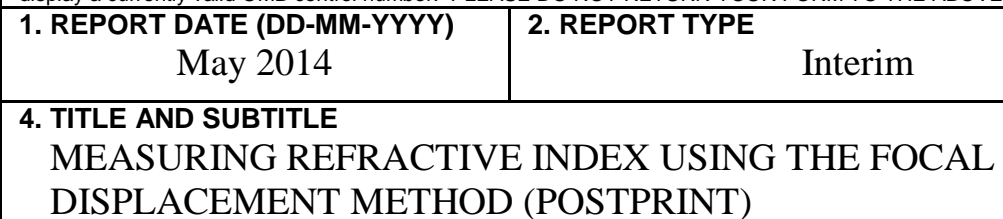

DISPLACEMENT METHOD (POSTPRINT)

3. DATES COVERED (From - To)

14 January 2011 - 22 April 2014

5a. CONTRACT NUMBER

FA8650-11-D-5400-0001

5b. GRANT NUMBER

5c. PROGRAM ELEMENT NUMBER

62102F

6. AUTHOR(S)

(see back) 5d. PROJECT NUMBER

4348

5e. TASK NUMBER

5f. WORK UNIT NUMBER

XODY

8. PERFORMING ORGANIZATION REPORT NUMBER

(see back)

10. SPONSOR/MONITOR'S ACRONYM(S)

9. SPONSORING / MONITORING AGENCY NAME(S) AND ADDRESS(ES)

Air Force Research Laboratory

Materials and Manufacturing Directorate

Wright Patterson Air Force Base, OH 45433-7750

Air Force Materiel Command

United States Air Force

AFRL/RXAP

11. SPONSOR/MONITOR'S REPORT NUMBER(S) AFRL-RX-WP-JA-2014-0208

12. DISTRIBUTION / AVAILABILITY STATEMENT

Distribution A. Approved for public release; distribution unlimited. This report contains color.

13. SUPPLEMENTARY NOTES

PA Case Number: 88ABW-2014-2747; Clearance Date: 5 June 2014. Journal article published in Applied Optics

Vol. 53, No. 17, 10 June 2014. (C) 2014 Optical Society of America. The U.S. Government is joint author of the work and has the right to use, modify, reproduce, release, perform, display or disclose the work. The final publication is available at http://dx.doi.org/10.I364/AO.53.003748.

14. ABSTRACT

A simple technique is introduced for measuring the refractive index of plane-parallel samples having thickness of the order of a millimeter. The refractive index values are reported for six bulk semiconductors, each index measured at two infrared wavelengths using this method. The values are found to be within a few percent of those in literature for four semiconductors. The other two semiconductors were newly grown ternary alloys (CdMgTe and CdMnTe), for which the refractive index values have not been reported previously at the wavelengths studied here.

\section{SUBJECT TERMS}

instrumentation, measurement, metrology

\begin{tabular}{|c|c|c|c|c|c|}
\hline \multicolumn{3}{|c|}{ 16. SECURITY CLASSIFICATION OF: } & \multirow{2}{*}{$\begin{array}{l}\text { 17. LIMITATION } \\
\text { OF ABSTRACT } \\
\text { SAR }\end{array}$} & \multirow{2}{*}{$\begin{array}{l}\text { 18. NUMBER } \\
\text { OF PAGES } \\
9\end{array}$} & \multirow{2}{*}{$\begin{array}{l}\text { 19a. NAME OF RESPONSIBLE PERSON (Monitor) } \\
\text { Shekhar Guha } \\
\text { 19b. TELEPHONE NUBER (include area code) } \\
\text { (937) }\end{array}$} \\
\hline $\begin{array}{l}\text { a. REPORT } \\
\text { Unclassified }\end{array}$ & $\begin{array}{l}\text { b. ABSTRACT } \\
\text { Unclassified }\end{array}$ & $\begin{array}{l}\text { c. THIS PAGE } \\
\text { Unclassified }\end{array}$ & & & \\
\hline
\end{tabular}




\section{REPORT DOCUMENTATION PAGE Cont'd}

6. AUTHOR(S)

Shekhar Guha - Materials and Manufacturing Directorate, Air Force Research Laboratory, Functional Materials Division

Joel M. Murray, Jean Wei, and Jacob O. Barnes - UES, Inc.

Jonathan E. Slagle - Leidos Corporation

7. PERFORMING ORGANIZATION NAME(S) AND ADDRESS(ES)

\section{AFRL/RXAP}

Air Force Research Laboratory

Materials and Manufacturing Directorate

Wright-Patterson Air Force Base, OH 45433-7750

UES Incorporated

4401 Dayton Xenia Road

Beavercreek, Ohio 45432

Leidos Corporation

5100 Springfield Street

Dayton, Ohio 45431 


\title{
Measuring refractive index using the focal displacement method
}

\author{
Joel M. Murray, ${ }^{1,3}$ Jean Wei, ${ }^{1,3}$ Jacob O. Barnes, ${ }^{1,3}$ Jonathan E. Slagle, ${ }^{2,3}$ and \\ Shekhar Guha ${ }^{3}$ \\ 'UES, Inc., Dayton, Ohio 45432, USA \\ ${ }^{2}$ Leidos Corp., Dayton, Ohio 45431, USA \\ ${ }^{3}$ Air Force Research Laboratory, Wright-Patterson AFB, Ohio 45433, USA \\ Received 25 March 2014; accepted 22 April 2014; \\ posted 5 May 2014 (Doc. ID 208746); published 10 June 2014
}

\begin{abstract}
A simple technique is introduced for measuring the refractive index of plane-parallel samples having thickness of the order of a millimeter. The refractive index values are reported for six bulk semiconductors, each index measured at two infrared wavelengths using this method. The values are found to be within a few percent of those in literature for four semiconductors. The other two semiconductors were newly grown ternary alloys $(\mathrm{CdMgTe}$ and $\mathrm{CdMnTe})$, for which the refractive index values have not been reported previously at the wavelengths studied here. (C) 2014 Optical Society of America

OCIS codes: (160.6000) Semiconductor materials; (160.4670) Optical materials; (120.0120) Instrumentation, measurement, and metrology.

http://dx.doi.org/10.1364/AO.53.003748
\end{abstract}

\section{Introduction}

The minimum deviation method [1,2] is a standard technique for measuring the refractive index of optical materials with high accuracy. However, many materials, especially those newly fabricated in limited size, are often not available in a prism shape and in sufficiently large dimensions to use this method. Techniques utilizing the Lau effect [3] or employing Michelson or Fabry-Perot interferometry [늠 can be used for refractive index measurement of plane-parallel samples, but the experimental setups for such interferometric methods are somewhat complicated.

For some applications, such as when a material is used as a window, it is unnecessary to know the refractive index value to a high degree of precision. In this paper we describe a technique that is simple in concept and provides the refractive index values within a few percent accuracy without the need to construct a prism from the material. The feasibility

$1559-128 \mathrm{X} / 14 / 173748-05 \$ 15.00 / 0$

(C) 2014 Optical Society of America of the technique is demonstrated and it is used to measure the refractive index values of recently fabricated ternary alloy semiconductors CdMgTe and CdMnTe.

\section{Principle}

Suppose a Gaussian beam in the air is incident upon a thin lens with a focal length $f$, and a transparent plane-parallel sample with refractive index $n$ and thickness $d$ is inserted normally in the beam at a distance $L$ from the lens, with $L<f$ as shown in Fig. 1. Under paraxial conditions, propagation of light through the sample is equivalent to propagating through a distance $d / n$ in air [7], assuming the refractive index of air to be unity. Thus, when the sample is inserted, the position of the beam focus shifts farther away from the lens by a distance

$$
\Delta z=d-\frac{d}{n}=d\left(1-n^{-1}\right)
$$

By experimentally measuring the sample thickness $d$ and the focal displacement $\Delta z$, the refractive index can be obtained using Eq. (1). 


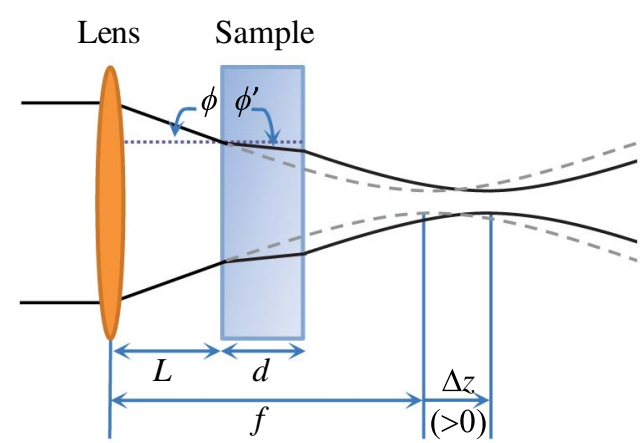

Fig. 1. Sample-induced focal shift.

For strongly convergent beams for which the paraxial condition is violated, marginal rays undergo a different axial shift than paraxial rays. An incident ray making an angle $\phi$ with respect to the sample normal will be refracted to an angle $\phi^{\prime}$ in the sample, and the exiting ray is shifted in $z$ a distance [8]

$$
\Delta z=d\left(1-n^{-1}\left(\frac{\cos \phi}{\cos \phi^{\prime}}\right)\right)
$$

The resulting focal shift must be calculated numerically for such cases. However, for propagation of light between planes in the focal region, the paraxial approximation can remain valid even for strongly focused beams [9] and for a sample placed near the focus, Eq. (1) remains a valid expression for the focal displacement, as the paraxial limit of Eq. (2). Physical optics modeling using the commercial software Zemax [10] confirms that in the paraxial limit, the focal shifts observed with the sample position fixed immediately after the lens match those observed when the sample is translated with the detector through focus.

\section{Experiment}

Sample thickness $(d)$ was measured for each sample using a Beta LaserMike optical micrometer (Model 60-05-01). Focal displacement $(\Delta z)$ in the presence and the absence of the sample was determined by the axial translation of a detector with a pinhole, as described below in detail.

The laser beams used had wavelengths of $4.8,4.64$, and $3.39 \mu \mathrm{m}$ and were obtained from a pulsed frequency-doubled Laser Science TEA $\mathrm{CO}_{2}$ laser, a frequency-doubled quasi-continuous wave Coherent DEOS Mid-IR-2 $\mathrm{CO}_{2}$ laser, and a continuous wave Research Electro-Optics He:Ne laser, respectively. The frequency-doubled Laser Science beam had a pulse duration of about $80 \mathrm{~ns}$ and a pulse repetition rate of $5 \mathrm{~Hz}$, and the Coherent DEOS and Research Electro-Optics laser beams were chopped at a frequency of $50 \mathrm{~Hz}$. In each case, the laser beam was spatially filtered (producing a Gaussian-like beam), collimated, attenuated if necessary, and steered by gold mirrors to illuminate a $1^{\prime \prime}$ diameter antireflection coated aspherical ZnSe lens (ISP Optics) having a $1^{\prime \prime}$ focal length (see Fig. 2). The Rayleigh

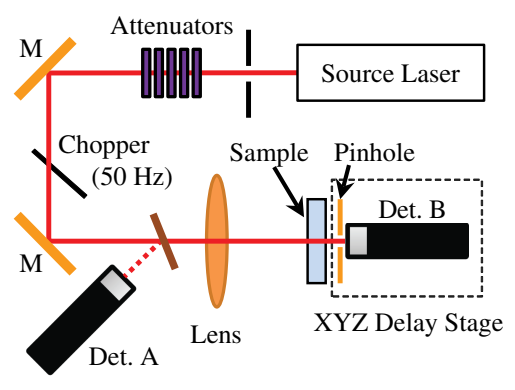

Fig. 2. Experimental setup.

ranges in air were 135,388 , and $69 \mu \mathrm{m}$ at the wavelengths of $4.8,4.64$, and $3.39 \mu \mathrm{m}$, respectively. The laser beams were aligned along the $z$-axis of the translation stage to minimize detector walk-off.

When the paraxial condition is met, Eq. (1) is valid for any sample position between the lens and its focus. However, due to the size of the sample mount and the short focal length of the lens, placing the sample at a fixed position after the lens limited the distance through which the detector could be translated. To increase this distance, the sample was mounted on the pinhole-detector combination, and the three elements were moved together. The laser power was maintained at values low enough to ensure that no nonlinear effects occurred during these experiments.

The focal position was determined by measuring the beam transmission through a pinhole, probed by a detector "B". To account for any fluctuations in the incident laser power, a beam-splitter was used to reflect part of the beam onto a detector "A". The recorded signal was the ratio of the two detector measurements, B/A.

For detector $\mathrm{B}$, a $\mathrm{PbSe}$ photodiode was used (ThorLabs PDA 20H). The photodiode signal was measured by a digital lock-in amplifier (Stanford Research Systems SR830) in the case of the 4.64 and $3.39 \mu \mathrm{m}$ laser beams, and by a digital oscilloscope (Tektronix TDS 5104) in the case of the pulsed $4.8 \mu \mathrm{m}$ beam. For the 4.8 and $4.64 \mu \mathrm{m}$ lasers, detector A was a photodiode (Boston Electronics PVM-10.6) connected to the Tektronix TDS 5104 oscilloscope; for the $3.39 \mu \mathrm{m}$ laser, stability was such that no

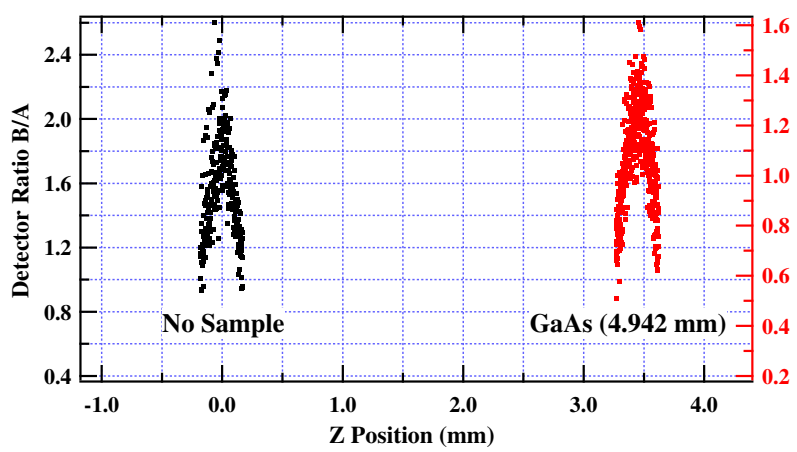

Fig. 3. Displacement scan at $4.64 \mu \mathrm{m}$ with and without GaAs sample. The right axis gives the scale (a.u.) when the sample is present (Fresnel losses). 
Table 1. Measured Refractive Indices Using the Focal Displacement Method and Comparison to Published Result

\begin{tabular}{|c|c|c|c|c|c|c|c|}
\hline Sample & Thickness (mm) & $\lambda(\mu \mathrm{m})$ & $\Delta z(\mathrm{~mm})$ & $n_{\text {exp }}$ & $\delta n_{\exp } / n_{\exp }$ & $n_{\text {pub }}$ & Error \\
\hline \multirow[t]{2}{*}{$\mathrm{Ge}$} & 1.235 & 3.39 & 0.93 & 4.10 & $3.9 \%$ & $4.034[12]$ & $1.5 \%$ \\
\hline & & 4.8 & 0.91 & 3.83 & $3.9 \%$ & $4.018[\overline{12}]$ & $4.7 \%$ \\
\hline \multirow[t]{2}{*}{$\mathrm{CdTe}$} & 2.251 & 3.39 & 1.42 & 2.69 & $1.2 \%$ & $2.695[\overline{13}]$ & $0.1 \%$ \\
\hline & & 4.8 & 1.41 & 2.68 & $1.2 \%$ & $2.683[\overline{13}]$ & $0.2 \%$ \\
\hline InAs & 1.006 & 4.64 & 0.71 & 3.40 & $7.3 \%$ & $3.475[\overline{14}]$ & $2.0 \%$ \\
\hline GaAs & 4.942 & 4.64 & 3.43 & 3.28 & $2.2 \%$ & $3.298[\overline{11}]$ & $0.6 \%$ \\
\hline
\end{tabular}

reference detector was required (i.e., the "A" signal was assumed constant).

The PbSe photodiode (B) was placed behind a $5 \mu \mathrm{m}$ diameter pinhole and mounted on an $x y z$ stage. The pinhole diameter was smaller than the beam waist diameters $\left(\mathrm{FW} e^{-2} \mathrm{M}\right)$ of approximately 25,53 , and $20 \mu \mathrm{m}$ at the wavelengths of $4.8,4.64$, and $3.39 \mu \mathrm{m}$, respectively. With the pinhole-detector combination near focus, the $x$ - and $y$-positions were adjusted to maximize the signal B/A. The signal was then recorded at each $z$-position, and the position of the peak indicated the focal position. The measurement was repeated with the sample mounted on the front of the pinhole. The difference in focal positions, with and without the sample, is the focal displacement $\Delta z$. From the values of $\Delta z$ and $d$ for each sample, the value of $n$ was calculated using Eq. (1).

\section{Results and Discussion}

Measurements were conducted first for four samples of materials with refractive index values known from the literature. These were Ge, CdTe, InAs, and GaAs. This technique was then used to measure the index values of two newly grown ternary semiconductors, CdMgTe and CdMnTe, for which there are no bulk index values available. The laboratory temperature during these measurements was $19^{\circ} \mathrm{C}$.

Typical data is shown in Fig. 3 where the relative energy transmitted through the pinhole is plotted as a function of the axial distance, with and without a GaAs sample (II-VI, Inc.) mounted in front of the pinhole. The sample was $4.942 \pm 0.004 \mathrm{~mm}$ thick and the sample-induced focal displacement was $3.43 \mathrm{~mm}$-corresponding to a refractive index of $3.28 \pm 0.07$ [Eq. (1)]. Compared with the accepted

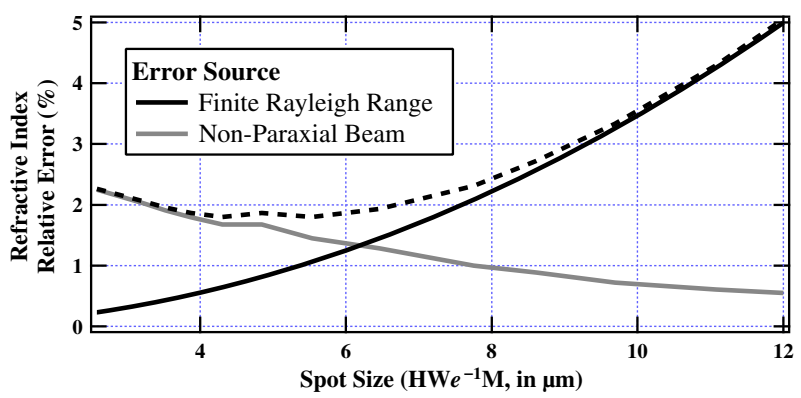

Fig. 4. Calculated relative errors owing to finite Rayleigh range (black) and the use of the paraxial approximation (gray). The dashed curve represents their sum in quadrature. Calculation is for a $d=3 \mathrm{~mm}$ GaAs sample at $\lambda=3.39 \mu \mathrm{m}$. value of 3.298 [11] (at $19^{\circ} \mathrm{C}$ ), this measurement has an error of $0 . \overline{6 \%}$.

Table 1 lists the results of measurements on GaAs and three other samples along with previously published refractive index values. Both the measurement uncertainties $(\delta n / n)[\underline{15}]$ and the errors (with respect to the published values) are within a few percent for all samples, indicating the validity of the method. The uncertainties were largest for $\mathrm{Ge}$ and InAs, arising from a wedge of $2.5 \mathrm{mrad}$ for the $\mathrm{Ge}$ sample and from the relatively small sample thickness $d$ for InAs (since the uncertainty depends on the ratio $\Delta z / d$ ). Measurement uncertainties can be reduced by using thicker samples with better surface parallelism.

For non-wedged samples, the standard deviation of the thickness measurement was $\sim 4 \mu \mathrm{m}$; for wedged samples, the uncertainties were greater $(\sim 10 \mu \mathrm{m}$ for the Ge sample studied). The thickness uncertainty can be reduced by improving the parallelism of the sample faces. The uncertainty in $\Delta z$ arises from the error in locating the focal position (which is a function of the Rayleigh range of the beam) and from the positioning errors due to the actuator and translation stage positioning.

Positioning uncertainty was minimized by allowing for actuator travel only in one direction. For the Newport LTA-HL precision motorized actuators used, the manufacturer's guaranteed actuator unidirectional repeatability was $\pm 0.25 \mu \mathrm{m}$ (3 sigma), or a standard deviation of $0.1 \mu \mathrm{m}$. The Newport 426 translation stage used has a pitch error less than $150 \mu \mathrm{rad}$. Since the pinhole was located $121 \mathrm{~mm}$ above the translation stage, the pitch retards or advances the pinhole less than $18 \mu \mathrm{m}$. Although this is an upper limit, it is rather large (a few percent of

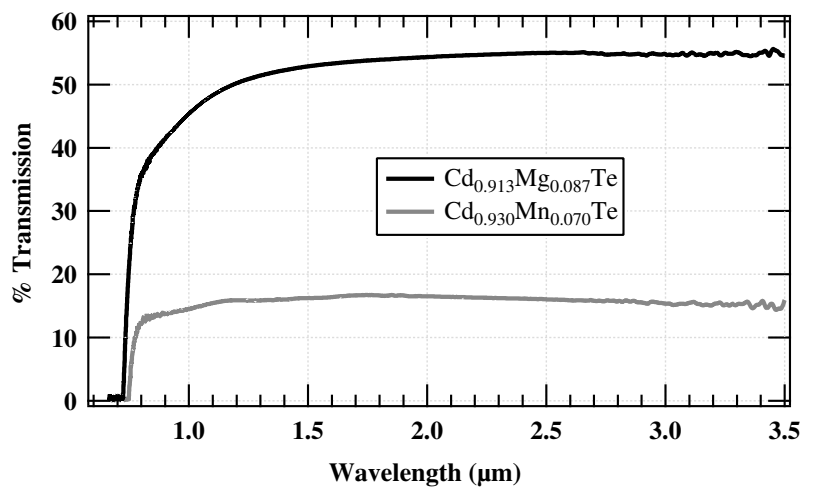

Fig. 5. Measured spectra for CdMgTe (black) and CdMnTe (gray). 
Table 2. Refractive Index of CdMgTe and CdMnTe at $292 \mathrm{~K}$ as Found Using the Focal Displacement Method

\begin{tabular}{lcccccc}
\hline Sample & Thickness $(\mathrm{mm})$ & Wedge $(\mathrm{mrad})$ & $\lambda(\mu \mathrm{m})$ & $\Delta z(\mathrm{~mm})$ & $n_{\exp }$ & $\delta n_{\exp } / n_{\exp }$ \\
\hline $\mathrm{Cd}_{0.913} \mathrm{Mg}_{0.087} \mathrm{Te}$ & 2.980 & 0.4 & 3.39 & 1.86 & $2.65 \pm 0.02$ & $0.8 \%$ \\
$\mathrm{Cd}_{0.930} \mathrm{Mn}_{0.070} \mathrm{Te}$ & \multirow{2}{*}{2.460} & 2.1 & 4.8 & 1.88 & $2.63 \pm 0.02$ & $0.9 \%$ \\
& & & 3.39 & 1.51 & $2.59 \pm 0.03$ & $1.1 \%$ \\
\hline
\end{tabular}

the typical $\sim 1 \mathrm{~mm}$ displacement distance) and may introduce systematic rather than random error. In spite of these large uncertainties shown in the column labeled $\delta n_{\exp } / n_{\exp }$ in Table 1 , the results presented here match the literature values to within $2 \%$ in all but one case. The exception was the measurement at $4.8 \mu \mathrm{m}$ of a Ge sample with known wedge $(2.5 \mathrm{mrad})$ and consequently larger thickness uncertainty.

To choose an appropriate spot size that minimizes the uncertainty in $\Delta z$, we note that while the focal positions can be located more precisely by minimizing the Rayleigh range, i.e., by reducing the focal spot size, for this simple technique to be applicable the spot size should not be reduced below the values for which Eq. (1) remains valid. For a sample of given thickness and for light of a given wavelength, the optimum Rayleigh range and spot size can be determined numerically. For example, for the case of GaAs at $3.39 \mu \mathrm{m}$ with a hypothetical sample thickness of $3 \mathrm{~mm}$, the relative error $\delta n / n$ with respect to the value $n=3.308[11]\left(19^{\circ} \mathrm{C}\right)$ was calculated for a range of beam radii at an $f=1^{\prime \prime}$ lens using a physical optics model in Zemax (Fig. 4). Also plotted in Fig. 4 is the calculated refractive index uncertainty, neglecting any thickness uncertainty, introduced by the finite Rayleigh range alone. (It was found empirically that the uncertainty of the focal position was approximately $12 \%$ of the Rayleigh range.) Although the former represents a systematic and the latter a random error, it is instructive to add the curves in quadrature (dashed curve), from which it is seen that a focal spot size of $5 \mu \mathrm{m}\left(\mathrm{HW} e^{-1} \mathrm{M}\right)$ is optimal. This corresponds to a Rayleigh range of $47 \mu \mathrm{m}$ and a $2.7 \mathrm{~mm}$ spot size at the lens.

Thus, the errors in the refractive index measurements can be reduced further from the measurements presented here by better sample polishing, faster focusing, lower pinhole placement, use of a translation stage with tighter tolerances, and using thicker samples if available.

The focal displacement method described above was used to measure the refractive index values for two newly grown samples of CdMgTe and CdMnTe. These materials show promise as x-ray and gammaray detector materials $[16,17]$ and also in nonlinear optics [18], but they are not easily available commercially. Their refractive indices are therefore not well known, and our review of the literature yielded no room temperature $\mathrm{CdMgTe}(\mathrm{CdMnTe})$ refractive index data at wavelengths longer than $1.8 \mu \mathrm{m}$ [19] $(2.5 \mu \mathrm{m}[20])$.
The CdMgTe and CdMnTe crystals were obtained from Brimrose Technology Corp. The linear transmission spectra of the two samples are shown in Fig. 5. Electron probe micro analyzer measurements revealed the CdMgTe sample to have a $\mathrm{Mg}$ fraction of 8.7\% and the CdMnTe sample to have a Mn fraction of $7.0 \%$. X-ray diffraction scans showed each sample to be a single crystal with orientation (110). Their refractive index values measured using the focal displacement method at two different wavelengths are listed in Table 2.

Both samples suffered from a slight wedge, and the uncertainty in the refractive index measurements was around $1 \%$, which is similar to that seen with the other samples. The results show that the refractive index values follow the trends shown in [19] and [20], and their wavelength dependence in the midwave infrared spectral region is relatively weak.

\section{Conclusion}

A simple method to measure the refractive index of plane-parallel materials is described. The method yields results accurate to within a few percent, and some ways to improve its accuracy were identified. The technique was demonstrated for materials with known refractive indices and for two ternary semiconductor compositions for which the refractive indices are not found in the literature. Use of a camera, as suggested by the work of Sun et al. [21], to locate the focal position will simplify the technique and possibly increase its accuracy.

The authors gratefully acknowledge Dr. Sudhir Trivedi (Brimrose Corp.) for providing the CdMgTe and CdMnTe samples, Dr. Jonathan Vernon (Air Force Research Laboratory) for the x-ray diffraction studies, Amelia Carpenter (UES, Inc.) for helpful discussions and Dr. Leonel Gonzalez (Air Force Research Laboratory) for many helpful suggestions and for critical reading of the manuscript.

\section{References and Notes}

1. D. T. F. Marple, "Refractive index of ZnSe, ZnTe, and CdTe," J. Appl. Phys. 35, 539-542 (1964).

2. D. E. Zelmon, E. A. Hanning, and P. G. Schunemann, "Refractive-index measurements and Sellmeier coefficients for zinc germanium phosphide from 2 to $9 \mu \mathrm{m}$ with implications for phase matching in optical frequency-conversion devices," J. Opt. Soc. Am. B 18, 1307-1310 (2001).

3. J. C. Bhattacharya, "Refractive index measurement," Opt. Laser Technol. 19, 29-32 (1987).

4. G. D. Gillen and S. Guha, "Use of Michelson and Fabry-Perot interferometry for independent determination of the refractive index and physical thickness of wafers," Appl. Opt. 44, 344-347 (2005). 
5. G. D. Gillen, C. DiRocco, P. Powers, and S. Guha, "Temperature-dependent refractive index measurements of wafershaped InAs and InSb," Appl. Opt. 47, 164-168 (2008).

6. H. J. Choi, H. H. Lim, H. S. Moon, T. B. Eom, J. J. Ju, and M. Cha, "Measurement of refractive index and thickness of transparent plate by dual-wavelength interference," Opt. Express 18, 9429-9434 (2010).

7. H. Kogelnik and T. Li, "Beams, Modes and Resonators," in Handbook of Lasers with Selected Data on Optical Technology, R. Pressley, ed. (CRC Press, 1971), pp. 421-441.

8. F. A. Jenkins and H. E. White, Fundamentals of Optics (McGraw-Hill, 1957).

9. S. Guha, "Validity of the paraxial approximation in the focal region of a small-f-number lens," Opt. Lett. 26, 1598-1600 (2001).

10. Zemax, LLC, www.zemax.com.

11. T. Skauli, P. S. Kuo, K. L. Vodopyanov, T. J. Pinguet, O. Levi, L. A. Eyres, J. S. Harris, M. M. Fejer, B. Gerard, L. Becouarn, and E. Lallier, "Improved dispersion relations for GaAs and applications to nonlinear optics," J. Appl. Phys. 94, 6447-6455 (2003).

12. H. W. Icenogle, B. C. Platt, and W. L. Wolfe, "Refractive indexes and temperature coefficients of germanium and silicon," Appl. Opt. 15, 2348-2351 (1976).

13. P. Hlidek, J. Bok, J. Franc, and R. Grill, "Refractive index of CdTe: spectral and temperature dependence," J. Appl. Phys. 90, 1672-1674 (2001).

14. S. Adachi, "Optical dispersion relations for $\mathrm{GaP}, \mathrm{GaAs}, \mathrm{GaSb}$, InP, InAs, InSb, $\mathrm{Al}_{\mathrm{x}} \mathrm{Ga}_{1-\mathrm{x}} \mathrm{As}$, and $\mathrm{In}_{1-\mathrm{x}} \mathrm{Ga}_{\mathrm{x}} \mathrm{As}_{\mathrm{y}} \mathrm{P}_{1-\mathrm{y}}$ ” J. Appl. Phys. 66, 6030-6040 (1989).

15. From Eq. (1), the refractive index is given by $n=(1-\Delta z / d)^{-1}$. With the reasonable assumption that the thickness measurement errors are normally distributed and uncorrelated with $\Delta z$, the relative uncertainty $\delta n / n$ in the refractive index is

$$
\frac{\delta n}{n}=n^{-1} \sqrt{\left(\frac{\partial n}{\partial d} \delta d\right)^{2}+\left(\frac{\partial n}{\partial \Delta z} \delta \Delta z\right)^{2}}=\frac{n}{d} \sqrt{\left(\frac{\Delta z}{d} \delta d\right)^{2}+(\delta \Delta z)^{2}} .
$$

The uncertainty $\delta \Delta z$ in the focal shift is given by

$$
\delta \Delta z=\sqrt{\delta z_{\text {sample }}^{2}+\delta z_{\text {nosample }}^{2}} \approx \delta z \sqrt{2},
$$

where we have explicitly assumed that the focal position measurement error $\delta z$ is unchanged by the presence of the sample.

16. A. Hossain, V. Yakimovich, A. E. Bolotnikov, K. Bolton, G. S. Camarda, Y. Cui, J. Franc, R. Gul, K.-H. Kim, H. Pittman, G. Yang, R. Herpst, and R. B. James, "Development of cadmium magnesium telluride $\left(\mathrm{Cd}_{1-\mathrm{x}} \mathrm{Mg}_{\mathrm{x}} \mathrm{Te}\right)$ for room temperature $\mathrm{X}$ - and gamma-ray detectors,” J. Cryst. Growth 379, 34-40 (2013).

17. A. Mycielski, A. Burger, M. Sowinska, M. Groza, A. Szadkowski, P. Wojnar, B. Witkowska, W. Kaliszek, and P. Siffert, "Crystal growth and characterization of $\mathrm{Cd}_{0.8} \mathrm{Mn}_{0.2} \mathrm{Te}$ using vertical Bridgman method," Phys. Status Solidi C 5, 1578-1585 (2005).

18. L. Kowalczyk, "Second harmonic generation in $\mathrm{Cd}_{1-\mathrm{x}} \mathrm{Mn}_{\mathrm{x}} \mathrm{Te}$," J. Cryst. Growth 72, 389-392 (1985).

19. M. Luttmann, F. Bertin, and A. Chabli, "Optical properties of CdMgTe epitaxial layers: a variable-angle spectroscopic ellipsometry study,” J. Appl. Phys. 78, 3387-3391 (1995).

20. D. W. Schubert, M. M. Kraus, R. Kenklies, C. R. Becker, and R. N. Bicknell-Tassius, "Composition and wavelength dependence of the refractive index in $\mathrm{Cd}_{1-\mathrm{x}} \mathrm{Mn}_{\mathrm{x}} \mathrm{Te}$ epitaxial layers," Appl. Phys. Lett. 60, 2192-2194 (1992).

21. X. Sun, H. Ma, H. Ming, Z. Zheng, J. Yang, and J. Xie, "The measurement of refractive index profile and aberration of radial gradient index lens by using imaging method," Opt. Laser Technol. 36, 163-166 (2004). 